\title{
Effect of port injection pressure on mixture quality in Homogeneous charges compression ignition (HCCI) engine
}

\author{
S.Gowthaman ${ }^{\mathrm{a}^{*}}$, Gobikrishnan $\mathbf{U}^{\mathrm{b}}$ \\ ${ }^{a *}$ Associate Professor, ${ }^{b}$ Assistant Professor \\ ${ }^{a}$ Department of Automobile Engineering, ${ }^{b}$ Department of Mechanical Engineering \\ ${ }^{\mathrm{a}}$ Kalasalingam Academy of Research and Education, ${ }^{\mathrm{b}}$ Sona College of Technology \\ Tamilnadu, India. gowthammech@ @otmail.com
}

\begin{abstract}
The purpose of this study is to investigate the effect of fuel injection pressure on homogeneous charge formation and performance and emission characteristics of Homogeneous charge compression ignition engine. The fuel injection pressure is one of the primary parameter for improving the homogeneity of the mixture and governing the power output and emission characteristics of HCCI engine. In this investigation, diesel fuel was injected at different injection pressures as 2bar, 3bar, 4bar and 5bar respectively through by port fuel injector. The experimental investigations show that increasing the fuel injection pressure will promote the fuel to penetrate with air and creates well pre mixed air/fuel charge.

The result shows, the specific fuel consumption (SFC) of HCCI engine is slightly higher than the SFC of conventional diesel engine. The HCCI engine with $3 \mathrm{bar}$ injection pressure operated engine has lower SFC values compared to other injection pressure operated HCCI engine. The brake thermal efficiency of HCCI engine, operated with 3 bar injection pressure has maximum BTE values over the other injection pressure operated engine. From the result, it is observed that HCCI engine has lower smoke density values compared to conventional diesel engine and further reduced by increasing the fuel injection pressure. The 3bar injection pressure operated HCCI engine has emitted lower smoke density compared to other injection pressure operated HCCI engine. The 3 bar injection pressure operated HCCI engine has emitted maximum oxides of nitrogen (NOx) emissions than the other injection pressure operated HCCI engine. Other exhaust emissions of carbon monoxide (CO) and hydrocarbon (HC) emissions are increased when compared to convention diesel engine.

Keywords: Homogeneous charge compression ignition engine, Injection Pressure, Diesel, Percentage of homogeneity, Oxides of nitrogen, Smoke emission.
\end{abstract}

\section{INTRODUCTION}

Homogeneous charge compression ignition (HCCI) engine has the potential of reducing both nitrogen oxide (NOx) and smoke emissions simultaneously to a near zero level while maintaining high efficiency, providing one of the most promising ways for diesel engines to meet future emission regulations. Since HCCI diesel combustion occurs throughout the bulk of a lean mixture, which lowers the local combustion temperature, the NOx emissions are suppressed and the smoke emission is greatly reduced due to absence of local rich mixture. In HCCI combustion, there are some significant difficulties to be solved for efficient working of HCCI engine, such as homogeneous charge preparation, control of starting phase of combustion and control of the combustion rate and high level of hydrocarbon (HC) and carbon monoxide (CO) emissions (1-6).

In HCCI engine, the homogeneous charge can be prepared by the port fuel injection, but results in high $\mathrm{HC}$ and $\mathrm{CO}$ emissions (7). There are two main reasons for creating high $\mathrm{HC}$ and $\mathrm{CO}$ emissions in HCCI diesel engine, first reason is due to lower temperature near the piston wall, especially in the piston crevice. Second, one is due to the bulk fuel particle, which is injected by the port injector with low injection pressure (8-10). The bulk fuel particle is difficult to mix with air molecule and form homogeneous charge in a short time. So that the fuel has to be leave from the engine cylinder as unburned hydrocarbon after the combustion process. Therefore, the mixture preparation is one of the toughest problems in the implementation of HCCI diesel engine. These complication of HCCI engine, led the author of this paper to investigate the effect of fuel injection pressure on performance and emission characteristics of HCCI engine.

In conventional engines, the start of combustion timing can be controlled with spark plug and fuel injection timing for conventional SI and CI engines respectively. But, the HCCI mode engine does not have a direct method to control the start of combustion timing. The following parameters used to control the combustion phase of the HCCI engine, fuel characteristics, intake air temperature, air-fuel ratio, fuel injection timing, fuel injection pressure and fuel injection timing (11-14). Mancarso et al.[15] investigated the combustion behaviour of HCCI engine with different injection pressures as 400bar, 500bar, 600 bar and 700bar respectively. Where rapeseed methyl ester and diesel were used and injected earlier directly to the cylinder during the suction of the engine. From this investigation, the author resulted that, the exhaust emissions of NOx and smoke were reduced by increasing the injection pressure. At the same time minor reduction in carbon monoxide and $\mathrm{HC}$ emissions due to increase the injection pressure. From the literature survey, identified 
that increasing the fuel injection pressure can improvers the power output and may reduces the exhaust emissions.

The objective of this work is to investigate the performance and emissions characteristics of HCCI engine operate with different injection pressure and analysis the impact of different fuel injection pressure on HCCI engine performance and emissions. In this research work, diesel fuel injected on intake air stream with different injection pressure such as 2bar, 3bar, 4bar and 5bar and optimise the fuel injection pressure from the observed result.

Table 1: Engine specification

\begin{tabular}{|l|l|l|}
\hline SL.N & Parameters & Specification \\
\hline 1. & Make and model & Kirloskar SV1 \\
\hline 2. & General details & $\begin{array}{l}\text { Single cylinder, four stroke, } \\
\text { water cooled, port injection }\end{array}$ \\
\hline 3. & Bore & $87.5 \mathrm{~mm}$ \\
\hline 4. & Stroke & $110 \mathrm{~mm}$ \\
\hline 5. & Cubic capacity & 0.661 lit \\
\hline 6. & Rated output & $5.9 \mathrm{KW}$ at $1800 \mathrm{rpm}$ \\
\hline 7. & Compression ratio & $17.5: 1$ \\
\hline 8. & $\begin{array}{l}\text { Inlet valve open } \\
\text { BTDC }\end{array}$ & $4.5 \mathrm{Deg}$. \\
\hline 9. & $\begin{array}{l}\text { Inlet valve close } \\
\text { ABDC }\end{array}$ & $35.5 \mathrm{Deg}$. \\
\hline 10. & $\begin{array}{l}\text { Exhaust valve } \\
\text { open BBDC }\end{array}$ & $35.5 \mathrm{Deg}$. \\
\hline & \multicolumn{2}{|l}{} \\
\hline
\end{tabular}

\section{EXPERIMENTAL SETUP}

A single cylinder, four stroke, water-cooled, DI diesel engine was used in this research work. In addition, it was slightly modified as port fuel injected HCCI engine with DI injection system. The specifications of modified kirloskar SV1 engine is listed in table 1. Figure 1 shows the experiment set up of HCCI mode engine. In HCCI engine, homogeneous charge is created by electronic controlled fuel injector, which is adopted at intake manifold. The fuel injection timing is controlled by using electronic controlled unit.

One end of engine shaft is coupled with eddy current dynamometer for applying the load. The dynamometer is controlled by manually operated knob in the control penal; it is keep separately near to the test engine. The applying load on the engine is shown in $\mathrm{Nm}$ on digital meter. The entire test has to be carried out with the constant speed of 1800rpm. The engine speed is displaced in control penal. Engine cooling water Inlet temperature and outlet water temperature are measured by thermo couple. AVL Di-gas analyser was used to measure the exhaust emission from the HCCI mode engine such as $\mathrm{CO}, \mathrm{HC}, \mathrm{NOx}, \mathrm{CO}_{2}$ and $\mathrm{O}_{2}$.

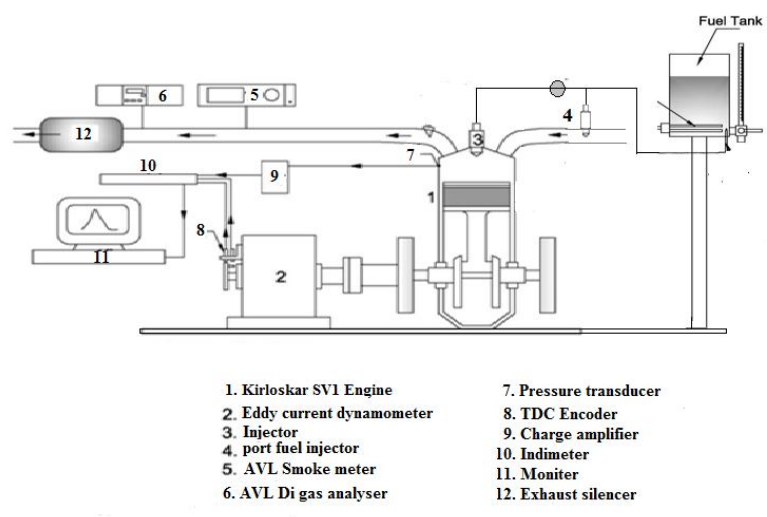

Figure 1: Experimental set up of Kirloskar SV 1 Engine

\section{EXPERIMENTAL PROCEDURE}

Initially the engine was operated under no load condition, since the engine reach the saturated engine temperature. The experimental investigations have been carried with different fuel injection pressures as 2 bar, 3 bar, 4 bar and 5bar and maintain the engine speed as constant of $1800 \mathrm{rpm}$. The manually controlled value is used to control the fuel injection pressure, the fuel injection pressure is indicated by pressure gauge is adopt in fuel line. The fuel injection timing is fully controlled by ECU, depends on the load and engine speed can change the injection timing and injection duration. The speed sensor or optical sensor is adopted near the engine crank shaft used to identify the engine speed and position of piston inside the cylinder. The output of the sensor is feed to the ECU, depends on the signal the ECU can change the fuel injection time and injection duration.

\section{RESULT AND DISCUSSION}

4.1 Fuel Penetration with Different Injection Pressure

Fig. 2 shows percentage of fuel penetration with air with different fuel injection pressure. The figure.1 indicates the fuel penetration is proportional to the injection pressure and inversely proportional to the ambient pressure. From this figure, it is observed that the fuel penetration percentage is only depending on fuel injection pressure. If the engine operates with lower injection pressure, injector injects the fuel as bulk molecules are very difficult to penetrate with air. In case of higher injection pressure, injector injects small fuel molecules on the inlet air, and form well pre mixed charge. The figure shows the fuel penetration is increasing during the suction and compression stroke. Because, during the suction stroke the premixed air-fuel charge enter into the combustion chamber with high intense swirl motion is promote the fuel penetration percentage. The rate of fuel penetrate with air is calculated by an empirical formula of Hiroyasu. The vaporisation percentage and spray penetration length are calculated from the diameter of injector nozzle hole and fuel injection pressure.

$$
\mathrm{t}_{\mathrm{b}}=28.65 \frac{\rho f D}{(\rho a(P f-P a))^{1 / 2}}
$$

$$
\mathrm{S}=0.2057 * 2 * \frac{(P f-P a)^{1 / 2}}{P f} * \mathrm{t} \quad\left(0<\mathrm{t}<\mathrm{t}_{\mathrm{b}}\right)
$$




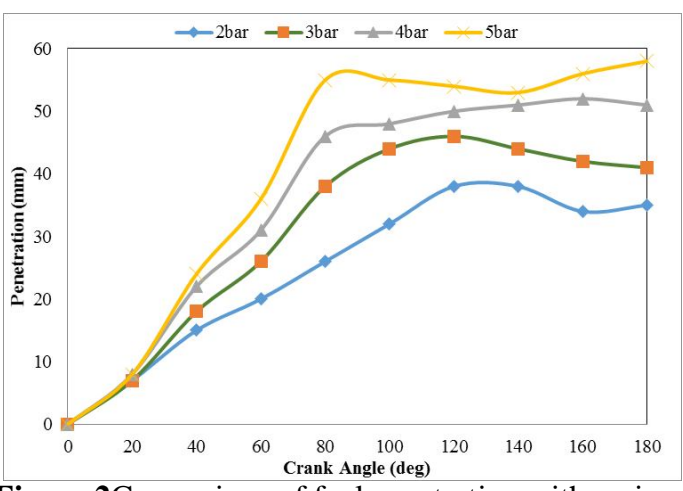

Figure.2Comparison of fuel penetration with various injection pressures

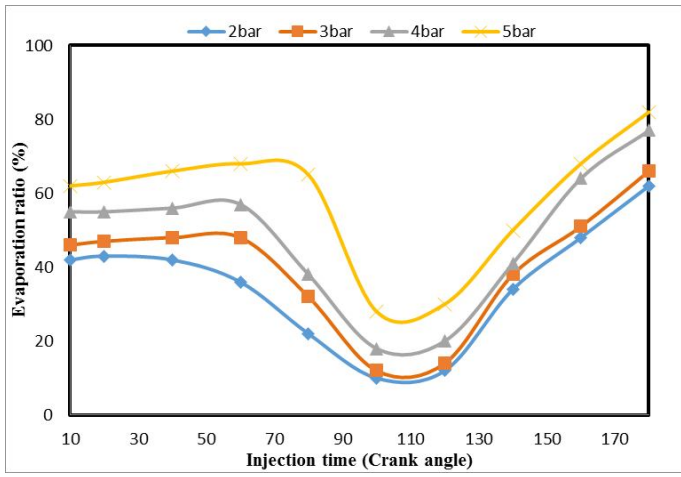

Figure.3Evaporation rate with injection pressure

Fig. 3 shows the evaporation percentage of fuel at different crank angle locations from the point of fuel injection to the start of ignition point. In HCCI engine operation, the port fuel injector injects the fuel during the suction cycle. After that, the fuel is going to be start vaporising by observed the heat of inlet air and cylinder wall. The figure indicates, evaporation ratio is increased with increasing the fuel injection pressure. The fuel evaporation percentage is one of the primary parameter to governing the engine power output and exhaust emissions. The highly evaporated fuel charge is called as homogeneous charge, if the engine operates with homogeneous charge can improves the power output and reduced the exhaust emissions of smoke, $\mathrm{CO}$ and $\mathrm{HC}$ emissions. At the same time Homogeneous charge is also have some difficulties to control the start of ignition and combustion process. If the air-fuel mixture gets higher percentage, lead to misfire the charge before the piston reaches the top death centre (TDC). Due to this, the engine has lost the power output, increased the smoke density and improved knocking intensity.

\subsection{Performance Characteristics}

Fig.4 shows the variation in specific fuel consumption (SFC) of different injection pressure operated HCCI engine. The result shows, the value of SFC for HCCI engine is slightly increased than the conventional diesel engine due to the poor combustion efficiency of HCCI engine. The other reason for increasing the SFC in HCCI mode engine is, the HCCI engine have done the combustion process by stating the ignition at various points in the combustion chamber. So that the fine fuel molecules are thoroughly mixed with air and accumulated with different air-fuel ratios that is some area having very lean region and some other area having very rich region.

During the compression cycle, the ignition is start from the rich region to lean charge region. At the time, some amount of fresh charge escape from the chamber during the exhaust cycle. Due to this reason, the HCCI engine has high SFC values for all operating condition of HCCI engine over the conventional engine. But the result indicates, 3bar injection pressure operated engine has lower SFC values beyond the $20 \%$ of load. The HCCI-3bar engine has consuming minimum amount of fuel for all load operations except $20 \%$ load compared to other injection pressure operated HCCI engine and convention engine.

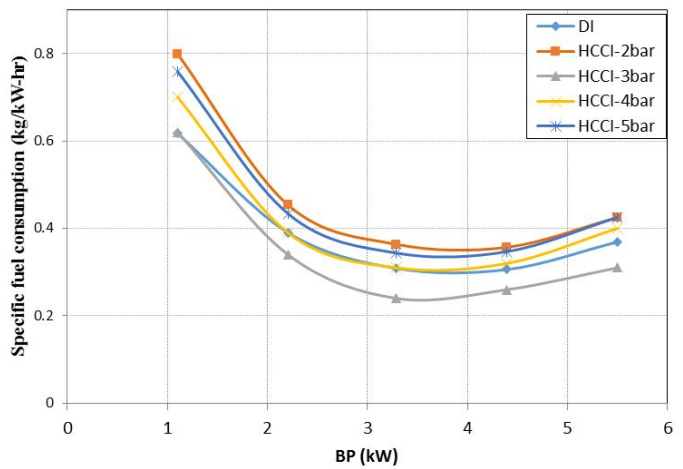

Figure.4Variation in specific fuel consumption with brake power

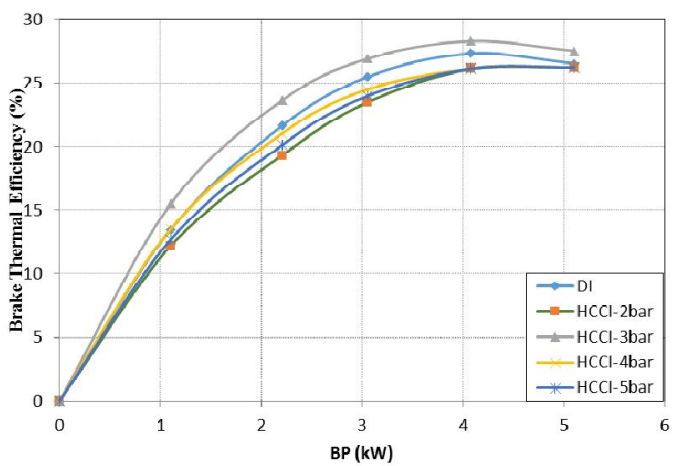

Figure.5Variation in Brake thermal efficiency with brake power

Fig.5 shows the variation in brake thermal efficiency (BTE)for different injection pressure operated HCCI engine with brake power. The HCCI-3bar engine has higher BTE values than the other injection pressure operated HCCI engine. The graph is also show the HCCI3bar engine has higher BTE than the convention diesel engine. The brake thermal efficiency is calculated by, amount of fuel is consumed by the engine and amount of energy is utilised by the engine during the combustion process. From the experimental result, it is observed that HCCI-3bar engine has high BTE with consuming minimum amount of fuel. Because, HCCI engine operated with 3 bar injection pressure, and the result indicates that it is enough pressure to inject the fuel and enough to make a fuel as fine molecule. These fine fuel molecules easily mixed with air and form premixed homogeneous charge. The homogeneous charge operated engine has improved the combustion efficiency and reduced the incomplete 
combustion and reduced the exhaust emissions except oxides of nitrogen.

\subsection{Emission Characteristics}

Variation in smoke density with brake power for different injection pressure operated HCCI engine is shown in figure.5. The result shows, diesel fuelled HCCI engine has emitted low smoke density than the conventional engine. The reason is, HCCI engine operates with homogeneous air-fuel charge minimise the incomplete combustion and improve the combustion efficiency. The main reason for smoke emission is insufficient amount of air present in the air-fuel mixture during the combustion process. due to insufficient amount of air, the charge is partially burnt and leave from the engine cylinder as carbon particle that is called smoke. The value of smoke density for different injection pressure operated HCCI engine is also shown in fig.6. The result shows, HCCI-3bar engine has low smoke density values compared to other injection pressure operated HCCI engine. Because, when the HCCI engine operated with 3bar fuel injection pressure, fuel is sprayed on the air as very small molecules and creates premixed charge. The imported note is the premixed charge take the combustion process before the charge reaches the misfire limit. So that HCCI-3bar engine shows lower smoke density values for all operating conditions as 4HSU, $\quad 8 \mathrm{HSU}, \quad 14 \mathrm{HSU}, \quad 16 \mathrm{HSU}$ and20HSUrespectively.

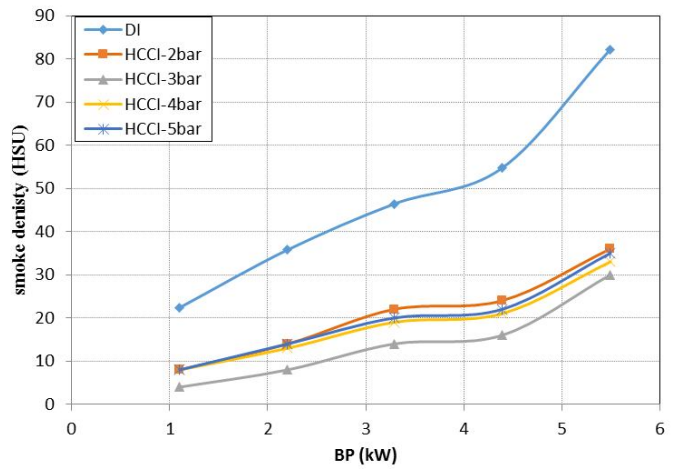

Figure.6 Variation in Smoke density with brake power

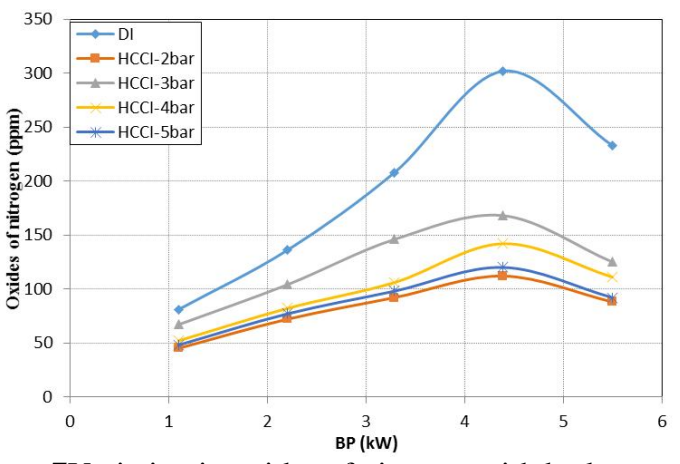

Figure.7Variation in oxides of nitrogen with brake power

Fig.7 shows variation in oxides of nitrogen for different injection pressures operated HCCI engine. One of the imported advantages of HCCI engine is low NOx emissions than the convention diesel engine. Similarly, in this investigation HCCI engine with different injection pressure operated engine have lower NOx emissions than the convention diesel engine. The injection pressure of 2bar and 5bar operated HCCI engine have minimum NOx values and HCCI-3bar shows higher NOx values than the other injection pressure operated HCCI engine. The reason for high NOx emission is the HCCI-3bar engine used better-premixed charge compared to other pressurised air/fuel charge. So that HCCI-3bar engine having better combustion efficiency and generated more heat energy and it leads to increase the oxides of nitrogen.

Fig.8 and Fig.9 are shows the variation in carbon monoxide (CO) and hydrocarbon (HC) emissions for different injection pressure operated HCCI engine. The result shows that HCCI engine has emitted more amounts of $\mathrm{CO}$ and $\mathrm{HC}$ emissions than the conventional diesel engine. From the result, HCCI-3bar operated engine shows lower $\mathrm{CO}$ emissions than the others injection pressure operated HCCI engine. There are two important reasons for $\mathrm{CO}$ formation in HCCI engine. First reason is, when the engine has insufficient amount of air in the combustion process, the engine will generates high $\mathrm{CO}$ emissions. Second reason is, the combustion process of HCCI engine take place at different location in the combustion chamber. The combustion chamber is having two different regions that is rich and lean air/fuel regions and combustion start initially from the rich region and spread whole area of the chamber. In this case, some amount of fresh charge escape from the cylinder without burn. These are the two main reasons for increasing the $\mathrm{CO}$ emission in 4 bar and 5bar injection pressure operated HCCI engine. However, fig. 8 shows, different injection pressure operated HCCI engine have higher $\mathrm{HC}$ emissions compared to convention engine.

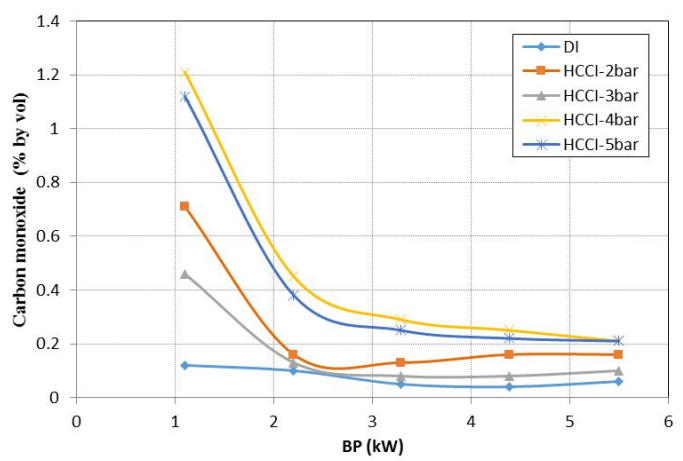

Figure.8Variation in carbon monoxide with brake power

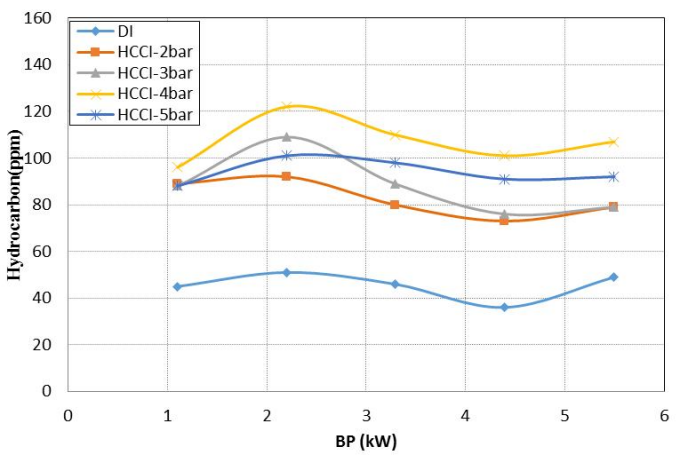

Figure.9Variation in hydrocarbon with brake power 


\section{CONCLUSION}

This work has been resulted that diesel can be effectively used in the HCCI mode engine with better performance and lower exhaust emissions than DI diesel engine. In this research further improved the power output and reduced exhaust emissions from the HCCI engine by increasing the fuel injection pressure. The conclusions of this research work are discussed below,

* The specific fuel consumption of HCCI with different injection pressure operated engine is slightly improved than the convention diesel engine, except HCCI-3bar engine. HCCI-3bar operated engine has lower SFC values for all operating conditions; the maximum reduction is $5 \%$ at $60 \%$ of load.

* The BTF of HCCI-3bar operated engine is slightly improved than the other HCCI operations. The HCCI3bar operated engine has higher BTE values for all loading conditions and improved the power output is about $10 \%$ higher than the conventional diesel engine.

* The values of smoke density for different injection pressure operated HCCI engine are lower than the conventional diesel engine. The HCCI with 3 bar fuel injection pressure operated engine having a maximum reduction in smoke for all operating conditions than the other injection pressure operated HCCI engine.

* CO emissions are increased, using HCCI engine with different fuel injection pressures compared to primary diesel engine. But, HCCI-3bar engine has reduced the $\mathrm{CO}$ emissions compared to other injection pressure operated HCCI engine. The maximum reduction take place at $20 \%$ of load is about 13 percentage compared to HCCI-4bar injection pressure operated engine.

* HC emissions from HCCI engine operated with different injection pressure are much higher than the convention diesel engine. HCCI-2bar injection pressure operated engine has lower value of $\mathrm{HC}$ emissions than the other HCCI operations.

\section{REFERENCES}

1. Epping K, Aceves S, Bechtold R, Dec J. The potential of HCCI combustion for high efficiency and low emissions.SAE Paper 2002-01-1923;2002.

2. Christensen $M$, Johansson B. Influence of mixture quality on homogeneous charge compression ignition.SAE paper 982454;1998.

3. Najt PE, Foster DE. Compression ignited homogeneous charge combustion.SAE Paper 830264; 1983.

4. Aceves SM, Flowers DL, Frias JM, Smith JR, Dibble $\mathrm{R}, \mathrm{Au}$ M, Girard J. HCCI combustion: analysis and experiments. SAE Paper, 2001-01-2077; 2001.[5] Thring R. Homogeneous charge compression ignition (HCCI) engines. SAE Paper 8902068; 1989.

5. Ryan TW, Callahan TJ. Homogeneous charge compression ignition of diesel fuel. SAE Paper 961160; 1996.

6. Ganesh D,Nagarajan G. Performance and emission analysis on mixed-mode homogeneous charge compression ignition(HCCI)combustion of biodiesel fuel with external mixture formation,SAE2011-01-2450;2011.

7. Senator A, Cardon M, Rocco V, Parti MV. A comparative analysis of combustion process in a DI diesel engine fuelled with biodiesel and diesel fuel. SAE paper no. 2000-01-0691; 2000.

8. Szybist JP, boehman AL, Behaviour of a diesel injection system with biodiesel fuel. SAE paper no. 2003-01-1039; 2003.

9. Boehman AL, morris D, szybist J, esen E. The impact of the bulk modulus of diesel fuels on fuel injection timing. Energy fuels 2004;18:1877-82.

10. Mingfa Yao, Zheng Chen, Zunqing Zheng, Bo Zhang, Yuan Xing. Study on the controlling strategies of homogeneous charge compression ignition combustion with fuel of dimethyl ether and methanol. Fuel 85 (2006) 2046-2056.

11. Christenson M, Hultqvist A, johnsson B. Demonstrating the multi fuel capability of a homogeneous charge compression ignition engine with variable compression ratio. SAE paper199901-3679, 1999.

12. Yao M,Zheng Z,Liu H. Progress and recent trends in homogeneous charge compression ignition(HCCI)engines.Prog Energy Combust Sci 2009;35:398-437.

13. Peng Z, Zhao H, Ladammator N. Effect of air-fuel ratios and EGR rates on HCCI combustion of nheptane,a diesel fuel. SAE paper 2003-01-0717, 2003.

14. E. Mancaruso, B.M. Vaglieco. Optical investigation of the combustion behaviour inside the engine operating in HCCI mode and using alternative diesel fuel. Experimental Thermal and Fluid Science 34(2010) 346-351. 